\title{
Improvement of solid particle erosion and corrosion resistance using TiAlSiN/Cr multilayer coatings
}

\author{
Jiabin $\mathrm{Gu}^{\mathrm{a}}$, Liuhe $\mathrm{Li}^{\mathrm{a}, *}$, Meng $\mathrm{Ai}^{\mathrm{a}}$, Yi Xu ${ }^{\mathrm{b}, \mathrm{c}}, \mathrm{Ye} \mathrm{Xu}^{\mathrm{a}, *}$, Guodong $\mathrm{Li}^{\mathrm{b}, \mathrm{c}}$, Dachen Deng ${ }^{\mathrm{a}}$, Hui Peng ${ }^{\mathrm{d}}$, \\ Sida Luo ${ }^{\mathrm{a}}$, Peipei Zhang ${ }^{\mathrm{a}}$

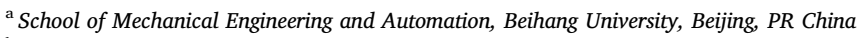 \\ ${ }^{\mathrm{b}}$ School of Engineering Science, University of Chinese Academy of Science, Beijing, PR China \\ ${ }^{\mathrm{c}}$ Institute of Mechanics, Chinese Academy of Sciences, Beijing, PR China \\ ${ }^{\mathrm{d}}$ School of Materials Science and Engineering, Beihang University, Beijing, PR China
}

\section{A R T I C L E I N F O}

\section{Keywords:}

TiAlSiN/Cr multilayer coatings

Toughness

Solid particle erosion

Corrosion performance

\begin{abstract}
A B S T R A C T
The TiAlSiN/Cr multilayer coatings with different thicknesses of chromium (Cr) layers were designed and prepared by high power impulse magnetron sputtering (HiPIMS) and direct current magnetron sputtering (DCMS) for the improvement of their solid particle erosion and corrosion resistance. The structure-property relationship was investigated by the systematic characterization of the microstructure, hardness, Young's modulus, toughness, solid particle erosion resistance, and corrosion properties of those coatings. The results reveal that the TiAlSiN layers consisted of the TiN crystalline phase and amorphous phase. As the Cr layers thickness increased, the grain growth of the $\mathrm{Cr}$ layers was columnar with a strong $\mathrm{Cr}$ (110)-preferred orientation. Compared with the TiAlSiN coating, the TiAlSiN/Cr multilayer coatings showed significantly improved toughness and corrosion performance. The toughness, $\mathrm{H} / \mathrm{E}$ ratio, erosion resistance at impact angle of $90^{\circ}$, and corrosion resistance of the TiAlSiN/Cr multilayer coatings firstly increased when the Cr layer thickness increased up to $21 \mathrm{~nm}$, before decreasing with a further increase of $\mathrm{Cr}$ layer thickness. Our results show that the TiAlSiN/Cr multilayer coatings with the $\mathrm{Cr}$ layer thickness of $21 \mathrm{~nm}$ exhibit enhanced toughness, excellent erosion resistance, and corrosion resistance together with high hardness.
\end{abstract}

\section{Introduction}

Solid particle erosion (SPE) and corrosion are common in many industries such as in aerospace, petrochemical, oil refinery, and power generation due to flowing corrosive media that often contain solid particles [1,3,2]. For example, the compressor blades of gas turbine aero-engines are often subjected to SPE and corrosion, particularly in dusty and salty-fog environments [3-5]. Those SPE- and corrosion-induced damages lead to a decrease in engine performance and service life, posting serious safety concerns [4-8]. Moreover, there appears to be a synergistic relationship between the corrosion and erosion, which accelerates the damage of the blades [8,9]. The erosion- and corrosionresistant coatings, particularly TiN-based coatings, such as TiN and TiAlN, have been considered to be the desirable solution for improving the erosion and corrosion resistance of compressor blades [10-13]. However, previous studies found the erosion resistance of these singlelayer coatings is often insufficient due to the lack of toughness, especially when being impacted at high angles by erodent particles [14,15].
To overcome this limitation, metal/ceramic multilayer structure coatings including Ti/TiN [16,17], Cr/CrN [18], TiAl/TiAlN [3], which exhibits both high hardness and high fracture toughness by combining advantages of the ceramic and metal components, have been proposed and attracted a lot of attention. Indeed, many studies have also shown that the metal/ceramic multilayer coatings have better erosion resistance than single-layer coatings [19-22]. Moreover, this multilayer structure can also be an effective method to enhance the corrosion resistance of the coatings. It has been found that the re-nucleation process occurring during the deposition of multilayer structure can significantly reduce pores found in coatings [23]. In addition, interfaces between layers can act as barriers for the corrosive medium to reach the substrate [24]. For example, Ti/TiN multilayer coatings have been studied as corrosion-resistant coatings for compressor blades and exhibit better corrosion resistance than TiN single layer [8].

The SPE and corrosion resistance of the metal/ceramic multilayer structure coatings can be further improved by the careful choices of metallic and ceramic materials. For the ceramic layers, TiAlSiN coatings

\footnotetext{
* Corresponding authors.

E-mail addresses: liliuhe@buaa.edu.cn (L. Li), ye.xu@buaa.edu.cn (Y. Xu).
} 
are particularly attractive due to their higher hardness, excellent tribological behavior, thermal stability, and corrosion resistance compared to TiN and TiAlN coatings [25-27]. K. Bobzin et al. [28,29] deposited nanocomposite TiAlSiN coatings by the high-speed physical vapor deposition and pointed out that TiAlSiN coatings had a promising potential for the erosion protection of compressor blades. For the metallic layers, it has been found that the metallic chromium may be partially converted to $\mathrm{Cr}_{2} \mathrm{O}_{3}$ during the chemical attack, which prevents further corrosion attack and potentially improves the corrosion performance of the coatings [30]. Despite the advantages of those two coating materials, few studies on the SPE and corrosion properties of the TiAlSiN/Cr multilayer coating have been conducted.

The novel high power impulse magnetron sputtering (HiPIMS) technology has been proven to be effective in preparing hard, dense, and growth defect (voids) free coatings, due to its high plasma density and ionization rate [31-34]. They have excellent erosion resistance and corrosion resistance [35,36]. The coatings prepared by DCMS technology generally have lower hardness and elastic modulus than the coatings prepared by HiPIMS technology [37]. The purpose of the softer and lower elastic modulus metal layers is the accommodation of relative sliding (shear strains) of the hard layers (ceramic layers) below and above, thereby preventing the build-up of high-bending stress [38]. Therefore, in this work, we designed and prepared the TiAlSiN/Cr multilayer coatings with different thicknesses of $\mathrm{Cr}$ layers by high power impulse magnetron sputtering (HiPIMS) and direct current magnetron sputtering (DCMS). We studied the microstructures and mechanical properties of those TiAlSiN/Cr multilayer coatings and, particularly, investigated the effect of the thickness of the $\mathrm{Cr}$ interlayers on the solid particle erosion and corrosion properties. Our results show that the TiAlSiN/Cr multilayer coatings with high hardness, improved toughness, as well as excellent erosion resistance and corrosion resistance can be obtained by optimizing the thickness of $\mathrm{Cr}$ layers.

\section{Experimental}

\subsection{Sample preparation}

The TiAlSiN/Cr multilayer coatings with different thicknesses of $\mathrm{Cr}$ layers were deposited onto M2 high-speed-steel substrate by a magnetron sputtering deposition system. As shown in the schematic in Fig. 1, the TiAlSiN layers were prepared by HiPIMS method using the rectangular $\mathrm{Ti}_{0.64} \mathrm{Al}_{0.3} \mathrm{Si}_{0.06}$ targets and the $\mathrm{Cr}$ layers were deposited by the conventional DCMS method using the rectangular Cr (99.99\% purity) targets. A detailed description of the system can be found in our earlier works $[39,40]$. Prior to deposition, all substrates were mechanically polished, ultrasonically cleaned, and etched by glow discharge for
Table 1

Processing parameters used in the preparation of TiAlSiN/Cr multilayer coatings.

\begin{tabular}{lllcl}
\hline \multirow{2}{*}{ Samples } & \multicolumn{2}{l}{ Deposition time (s) } & \\
\cline { 2 - 5 } & Cr buffer layer & CrN buffer layer & Cr layer & TiAlSiN layer \\
\hline S2 & 210 & 840 & 5 & 1200 \\
S3 & 210 & 840 & 10 & 1200 \\
S4 & 210 & 840 & 15 & 1200 \\
S5 & 210 & 840 & 20 & 1200 \\
\hline
\end{tabular}

$30 \mathrm{~min}$ at $1.5 \mathrm{~Pa}$ Ar pressure to remove surface contaminants and the surface oxidation layer. The vacuum chamber was evacuated to a base pressure of $3 \times 10^{-3} \mathrm{~Pa}$ for the preparation of the coatings and the temperature of the samples was kept constant at $150{ }^{\circ} \mathrm{C}$ during the deposition. To improve the adhesion, $\mathrm{Cr}+\mathrm{CrN}$ buffer layers were prepared by DCMS before the deposition of TiAlSiN coating and TiAlSiN/Cr multilayer coatings. For depositing $\mathrm{Cr}+\mathrm{CrN}$ buffer layers and metallic $\mathrm{Cr}$ interlayers, the average target current, bias voltage, and operating pressure were kept constant at $1.5 \mathrm{~A}, 65 \mathrm{~V}$, and $0.8 \mathrm{~Pa}$, respectively. For depositing TiAlSiN layers, pulse width, pulse frequency, bias voltage, supply voltage, and operating pressure were maintained constant at $300 \mu \mathrm{s}, 50 \mathrm{~Hz}, 300 \mathrm{~V}, 1000 \mathrm{~V}$, and $0.8 \mathrm{~Pa}$, respectively. The TiAlSiN/Cr multilayer coatings were prepared by rotating the substrate between each target. The processing parameters used in the synthesis of TiAlSiN/Cr multilayer coatings are listed in Table 1. The total deposition time of single-layer TiAlSiN coating, designated as Sample S1, was $120 \mathrm{~min}$. For TiAlSiN/Cr multilayer coatings designated as S2 to S5, the deposition time was $20 \mathrm{~min}$ for each TiAlSiN layer, and varied as $5 \mathrm{~s}$, $10 \mathrm{~s}, 15 \mathrm{~s}$, and $20 \mathrm{~s}$ for each $\mathrm{Cr}$ layer, corresponding to different samples. The choice of deposition times was to ensure the same thickness for each TiAlSiN layer and a range of different thicknesses of each $\mathrm{Cr}$ layer.

\subsection{Characterization and evaluation of the coatings}

A field emission scanning electron microscope (SEM) Zeiss Supra 55 was used to analyze the cross-sectional morphology and thickness of the coatings. The thickness of the $\mathrm{Cr}$ layer was determined by high magnification SEM cross-sectional images. The phase and crystalline structure of the coatings was identified by X-ray diffraction (XRD: D/ Max 2500) with CuKa radiation in grazing-incidence mode $\left(2^{\circ}\right)$. Nanoindentation tester (Nano-Indentor G200, Agilent) with a load precision of $50 \mathrm{nN}$ was used to evaluate the hardness and Young's modulus by continuous stiffness method (CSM). The penetration depth did not exceed $10 \%$ of the coating thickness in order to minimize the

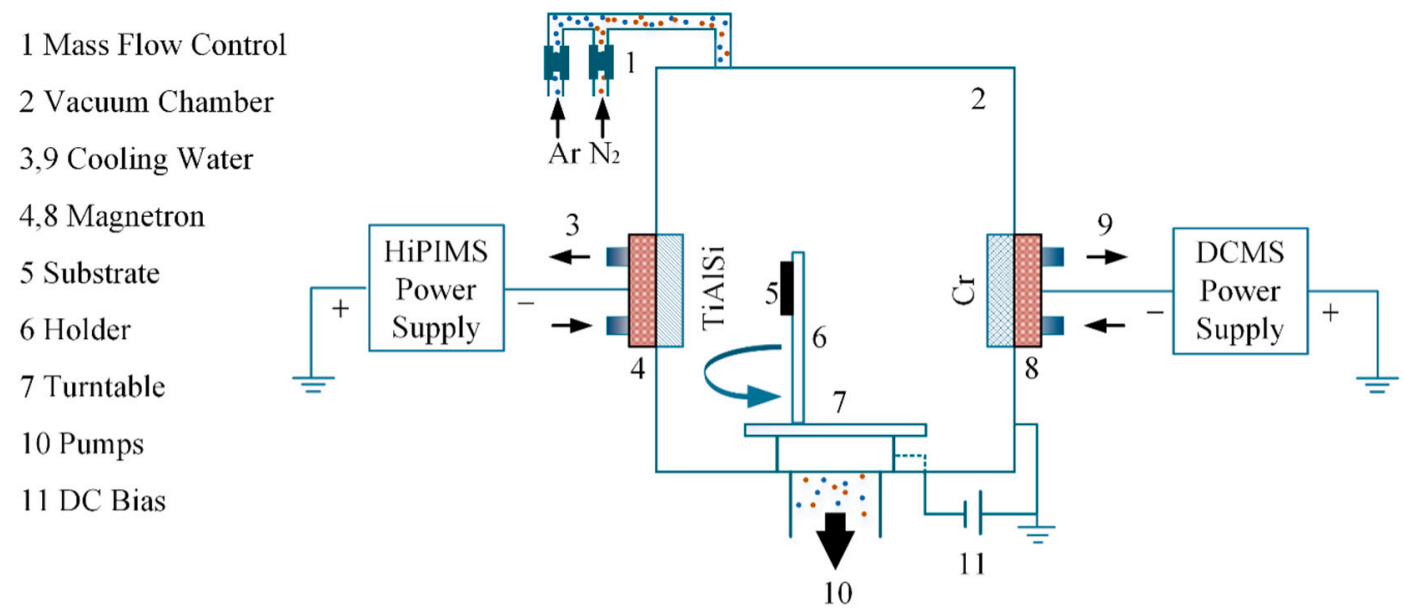

Fig. 1. Schematic of the deposition apparatus. 
effect of the substrate on the hardness measurement. The indentation toughness was determined using a micro Vickers tester (VickersIndentor, Wolpert-401MVD) with an applied load of $50 \mathrm{~g}$ and the Vickers indents were investigated by the SEM (Zeiss Supra 55). Nine indentations were made on each sample to obtain a mean value.

Sand erosion tests following the ASTM standard G76-13 [41] were performed at room temperature using angular alumina $\left(\mathrm{Al}_{2} \mathrm{O}_{3}\right)$ powders with an average size of $50 \mu \mathrm{m}$. A silicon carbide nozzle with an inner diameter of $1.5 \mathrm{~mm}$ and a length of $50 \mathrm{~mm}$ was utilized in the tests. During testing, the distance from the specimen surface to nozzle end was kept at $15 \pm 1 \mathrm{~mm}$. The coatings were tested at two impact angles, $30^{\circ}$ and $90^{\circ}$, with an average particle feed rate of $2 \mathrm{~g} / \mathrm{min}$. A set of particle impact velocities, 30,40 , and $50 \mathrm{~m} / \mathrm{s}$, were used for the tests and measured by using the rotating double-disk method [42]. The erosion tests were terminated before the tested coating was perforated. After the tests, the average mass loss was evaluated by comparing the weight of samples before and after testing using a precision balance with an accuracy of $10^{-5} \mathrm{~g}$. The erosion rates were then calculated by dividing the total mass loss by the total mass of the erodent particles. The corrosion behaviors of the coatings were investigated by a threeelectrode electrochemical test in $3.5 \% \mathrm{NaCl}$ solution at room temperature. The prepared sample was used as the working electrode, while a Pt mesh and a saturated calomel electrode (SCE) were used as the counter electrode and the reference electrode, respectively.

\section{Results and discussions}

\subsection{Microstructure of the TiAlSiN/Cr coatings}

The cross-sectional morphologies of TiAlSiN/Cr multilayer coatings with different thicknesses of $\mathrm{Cr}$ layers were observed by SEM and the micrographs are shown in Fig. 2. A columnar $\mathrm{Cr}+\mathrm{CrN}$ gradient buffer layer (about $900 \mathrm{~nm}$ in thickness) was visible between the coating and the substrate in all samples. For the single-layer TiAlSiN coating (Fig. 2a), a dense structure without columnar feature was observed, which is consistent with the nanocomposite (nc-TiAlN/a- $\mathrm{Si}_{3} \mathrm{~N}_{4}$ ) structure found in previous studies [40,43]. As shown in Fig. 2(b)-(f), the TiAlSiN/Cr multilayer structure can be clearly identified. The total thicknesses of the resulting coatings are measured to be $4.16,4.21$, $4.29,4.31$, and $4.32 \mu \mathrm{m}$. For the multilayer coatings (Fig. 2(b)-(e)), the same thickness of each TiAlSiN layer is confirmed and measured to be $550 \mathrm{~nm}$. For the $\mathrm{Cr}$ layers, as the deposition time increases from $5 \mathrm{~s}$ to $20 \mathrm{~s}$, the thicknesses are measured to be $10,21,30,41 \mathrm{~nm}$, respectively. Moreover, from the enlarged SEM images (Fig. 2(f)), the Cr layers in S5 were observed to demonstrate a columnar crystal structure.

Fig. 3 presents the XRD patterns of the single-layer TiAlSiN coating and TiAlSiN/Cr multilayer coatings. The peaks of TiN, $\mathrm{Cr}$, and substrate were identified and tagged. The single-layer TiAlSiN coating exhibited a preferred orientation of TiN (200), which, however, shows lower peaks in TiAlSiN/Cr multilayer coatings. This phenomenon may be due to the influence of $\mathrm{Cr}$ coverage. For the TiAlSiN/Cr multilayer coatings, the peaks for TiN (200) become stronger with the increase of the Cr layers thickness, which may be due to the changes in the residual stress of the multilayer coatings [44]. It is well known that the preferred orientation of the film grown by physical vapor deposition is decided by the conditions resulting in the lowest energy in a competition between the surface and strain energies [45]. The (200) plane has the lowest surface energy in the fcc lattice of NaCl-type crystal structure [46]. The surface energy shows a significant change with the different stress states [47]. And previous studies have found that as the thickness of the metal interlayer increases, the residual stress in the ceramic layer increases [48]. Compared with the TiAlSiN coating, the diffraction peak of TiN (200) of the TiAlSiN/Cr multilayer coatings shifts to higher $2 \theta$ angles, which may be due to the lower residual stress of the multilayer coating than that of the single-layer coating [49,50]. No visible peak of Si3N4 and TiSi crystalline phases were observed, suggesting that the silicon atoms are likely to exist in the form of amorphous silicon nitride (aSi3N4) or are incorporated in the FCC lattice, or both [39,51-54]. The peak of the HCP AlN phases are not observed neither, which may be due to the high $\mathrm{Ti} / \mathrm{Al}$ ratios. This result suggests that $\mathrm{Al}$ atoms are probably incorporated in the FCC lattice of TiN phase [55]. For the TiAlSiN/Cr multilayer coatings, the peaks for $\mathrm{Cr}$ (110), (200) and (211) gradually become higher and sharper as the deposition time of the $\mathrm{Cr}$ layers increased from $5 \mathrm{~s}$ to $20 \mathrm{~s}$, which is consistent with the increase of $\mathrm{Cr}$ content and coverage. In addition, with the increase of the $\mathrm{Cr}$ layers thickness, the peak of $\mathrm{Cr}$ (110) becomes more dominant comparing to the other two $\mathrm{Cr}$ peaks, indicating the stronger preferred orientation of (110) for thicker Cr layers.

\subsection{Mechanical properties of the TiAlSiN/Cr multilayer coatings}

Fig. 4 shows the hardness, Young's modulus, and H/E ratio of TiAlSiN coating and TiAlSiN/Cr multilayer coatings with different thicknesses of $\mathrm{Cr}$ layers. As expected, the single-layer TiAlSiN coating exhibited the maximum hardness $(34.5 \pm 0.8 \mathrm{GPa})$ and maximum Young's modulus $339 \pm 7.2 \mathrm{GPa}$. With the incorporation of softer metallic $\mathrm{Cr}$ layers, the hardness decreases from $32.7 \pm 1.0 \mathrm{GPa}$ to $23.4 \pm 2.1 \mathrm{GPa}$, as the thickness of Cr layers increases from $10 \mathrm{~nm}$ to $41 \mathrm{~nm}$. Correspondingly, Young's modulus of coatings also follows a similar trend of decreasing from $319 \pm 2.5 \mathrm{GPa}$ to $248 \pm 13 \mathrm{GPa}$ with increasing $\mathrm{Cr}$ layer thickness. However, the H/E ratio of coatings firstly increased with the incorporation and increase of the $\mathrm{Cr}$ layer thickness and reached their maximum values of 0.105 for $\mathrm{Cr}$ layers thickness of $21 \mathrm{~nm}$ before decreasing. The H/E ratio is related to the elastic strain to failure [56,57], where a higher $\mathrm{H} / \mathrm{E}$ value indicates a higher toughness [58-60]. The results suggest that, with the right thickness of the soft metallic Cr thickness, there is an optimal TiAlSiN/ $\mathrm{Cr}$ multilayer coatings with the maximal fracture toughness.

To further investigate the toughness of the coatings, the Vickers indentation method was conducted on the prepared samples. The micrographs of the residual indents generated by Vickers indenter are shown in Fig. 5. First of all, it can be seen that no radical cracks were found for all coating surfaces. As shown in Fig. 5(a), wide edge cracks (arrow) were observed just outside the contact area of the indentation. This is due to the hard and brittle nature of the TiN-type phases in the TiAlSiN coating which is prone to cracking when the coating is deflected under indentation [61]. Many fine cracks, which referred as continuous/discontinuous cracks elsewhere [62], were also found at near the center of the contact area of indent for the single-layer TiAlSiN coating. By contrast, only some fine edge cracks appear outside the indented areas in TiAlSiN/Cr multilayer coatings, with no fine cracks found within the contact area. The result here indicated that the TiAlSiN/Cr multilayer coatings exhibit better toughness than TiAlSiN coating. This improvement of toughness may come from interfaces between layers in the multilayer structure which can deflect the cracks and thus hinder the crack propagation across the thickness of the whole coatings $[63,64]$. In addition, the ductility of metallic chromium layers could also help absorb the strain energy during the indentation [21] and therefore reduce the TiN grain boundary sliding which facilitates fracture [65]. It is also worth noting that, among edge cracks were observed in Fig. 5(b), (d), and (e), those in Fig. 5(e) were appears wider. This change suggests that, with the further increase of the thickness of the $\mathrm{Cr}$ layers, the fracture toughness of the multilayer coating starts to decrease, possibly due to the low hardness of $\mathrm{Cr}$ layers and the mismatch of plastic deformation between layers [44]. Finally, we found the TiAlSiN/Cr multilayer coating with $\mathrm{Cr}$ layers thickness of $21 \mathrm{~nm}$ (Fig. 5c) showed minimal cracks after the indentation, which is consistent with the results of the H/E ratio measurements. Combining 

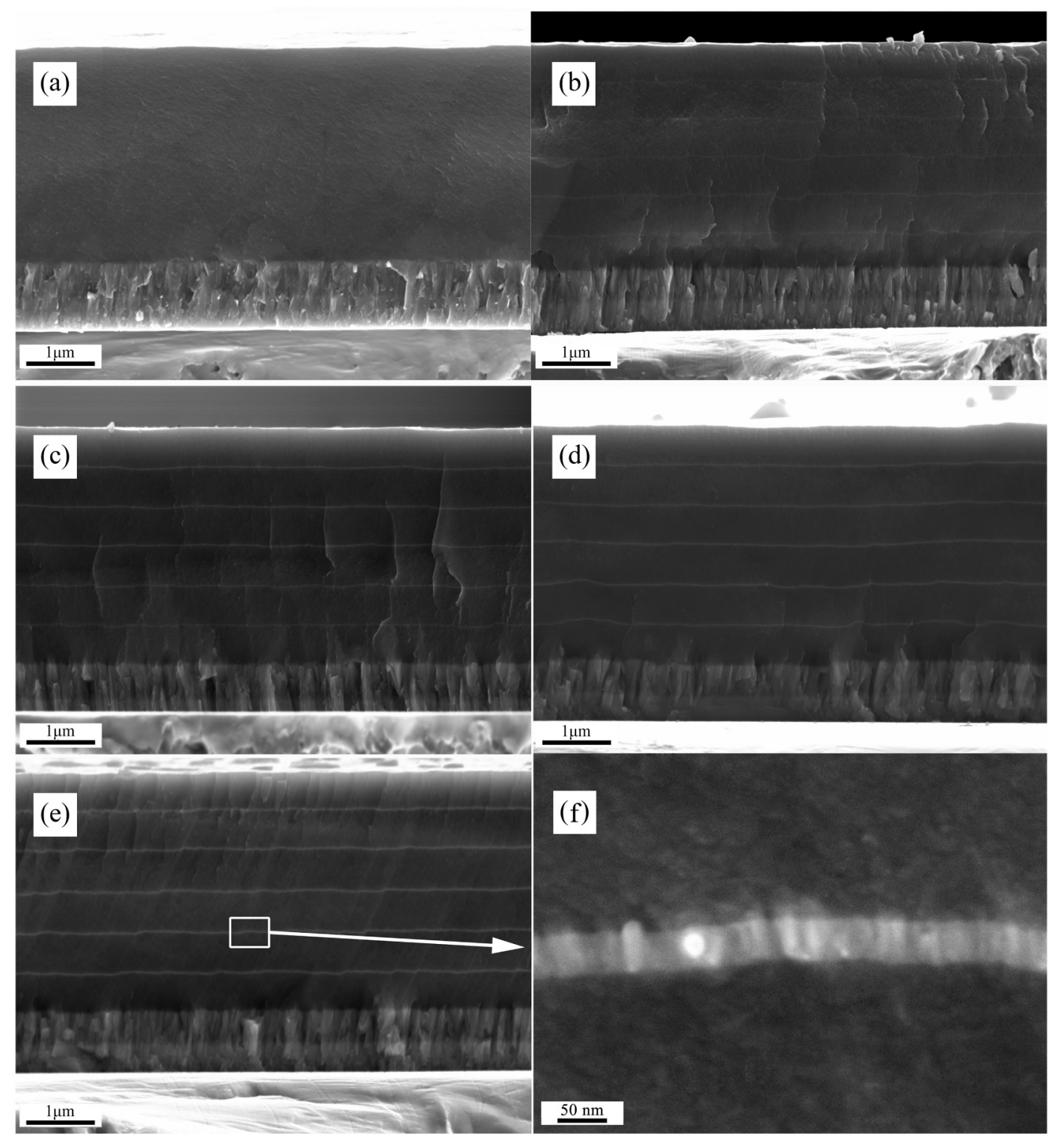

Fig. 2. Cross-sectional morphologies of TiAlSiN coating (a) and TiAlSiN/Cr multilayer coatings with different thicknesses of $\mathrm{Cr}$ layers of $10 \mathrm{~nm}$ (b), $21 \mathrm{~nm}$ (c), $30 \mathrm{~nm}$ (d), $41 \mathrm{~nm}(\mathrm{e})$, and ( $\mathrm{f}$ ) is the enlarged image of the rectangular region in (e).

similar results reported in Refs $[44,65]$ we believe that the H/E ratio is a good indicator of the fracture toughness of the coating.

Fig. 6 presents the erosion rates of TiAlSiN coating and TiAlSiN/Cr multilayer coatings with different thicknesses of $\mathrm{Cr}$ layers. It is known that the maximum erosion rate appears at the impact angle of $15^{\circ}-40^{\circ}$ for most ductile materials (such as metals), and $90^{\circ}$ for most brittle materials (such as ceramics) $[66,67]$. Therefore, two impact angles, $30^{\circ}$ and $90^{\circ}$, were chosen for the test. Different velocities of the impacting particles were tested as erosion damage strongly depends on the impact velocity $[68,69]$. We found that, when the impact angle was kept at $90^{\circ}$, the erosion rates of all coatings quickly increased with increasing impact velocity, similar to the exponential increases observed in previous studies $[70,71]$. This result is reasonable as the kinetic energy of impact particles and impacting force applied to the coatings increases with what square of the particle velocities [68]. When the performance of the coatings was compared at the same impact velocity at the impact angle of $90^{\circ}$, it was found that the coating with the Cr layers thickness of $21 \mathrm{~nm}$ showed the lowest erosion rate. This result shows an excellent agreement with the H/E ratio measurement and the observation of cracks under indentation, shown in Figs. 4 and 5. Indeed, the erosion damage process at a high impact angle is closely related to the toughness of the coatings [72-74]. By contrast, for the impact angle of $30^{\circ}$, the erosion rate of single-layer TiAlSiN coating is the smallest and that of TiAlSiN/Cr multilayer coatings increased with the increase of the $\mathrm{Cr}$ layers thickness. The different trends in those two impact angles are likely the results of two different mechanisms for the erosion damage: ductile-type damage is caused by cutting and brittle-type damage is caused by cracking. For semi-brittle materials (such as transition metal nitrides), cutting or plowing is the dominating erosion damage mechanism for low-angle impacts [72-74] and hardness is the most important factor in determining erosion resistance associated with cutting or plowing [15]. Therefore, coatings with higher hardness (Fig. 4) will result in a smaller penetration depth of high-speed solid particles, thus reducing the erosion rates caused by cutting at low impact angles [75]. 


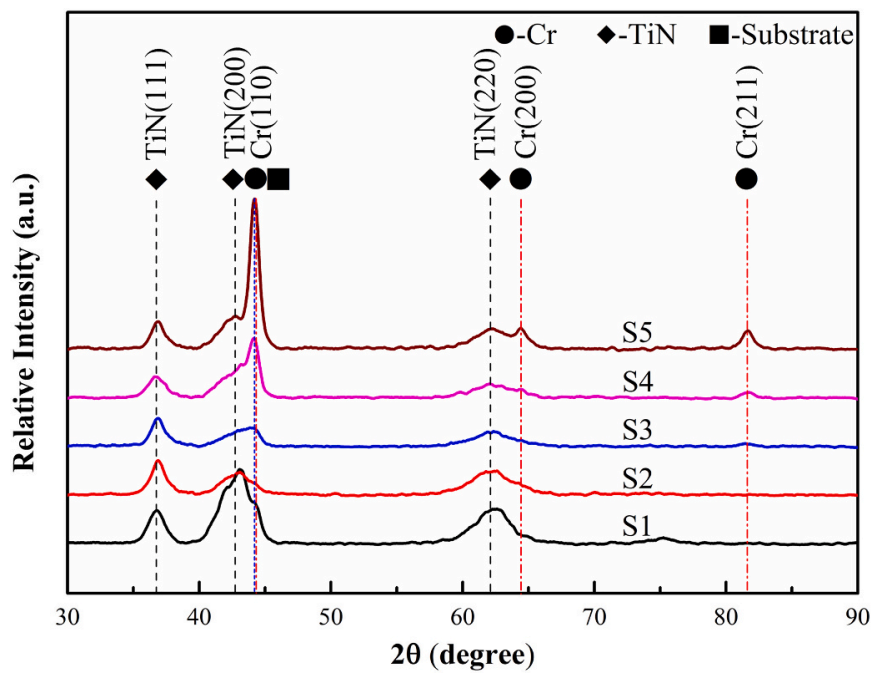

Fig. 3. The X-ray diffractometry patterns of TiAlSiN coating (S1) and TiAlSiN/ Cr multilayer coatings with different thicknesses of Cr layers of $10 \mathrm{~nm}$ (S2), $21 \mathrm{~nm}$ (S3), $30 \mathrm{~nm}$ (S4), and $41 \mathrm{~nm}$ (S5).

Considering the erosion rate of the TiAlSiN/Cr multilayer coating with the $\mathrm{Cr}$ layers thickness of $21 \mathrm{~nm}$ (Coating S3) was lowest at high-angle impact and only slightly higher than that of the single-layer TiAlSiN for low-angle impact, we believe it can perform best in comprehensive erosion resistance at different impact angles. Consistent with previous studies [73,74], our results showed that excellent erosion performance can be achieved by a good combination of high hardness and toughness in multilayer coatings consisting of hard and ductile layers.

Finally, the corrosion behaviors of our prepared coatings were evaluated. Fig. 7 shows potentiodynamic polarization curves of the TiAlSiN coating and TiAlSiN/Cr multilayer coatings with different thicknesses of $\mathrm{Cr}$ layers exposed to $3.5 \mathrm{wt} \% \mathrm{NaCl}$ solution. The corrosion potential $\left(\mathrm{E}_{\text {corr }}\right)$ and the corrosion current density $\left(\mathrm{I}_{\text {corr }}\right)$ of samples derived from polarization curves are summarized in Table 2. In general, a lower $\mathrm{I}_{\text {corr }}$ value indicates a better corrosion resistance [76]. The single-layer TiAlSiN coating exhibited a low corrosion potential $\left(\mathrm{E}_{\text {corr }}=-0.799 \mathrm{~V}\right)$ and a corrosion current density $\left(\mathrm{I}_{\text {corr }}=1.91 \times 10^{-6} \mathrm{~A} / \mathrm{cm}^{2}\right)$. In comparison, TiAlSiN/Cr multilayer coatings exhibited higher positive corrosion potentials and lower corrosion current densities, indicating that TiAlSiN/Cr multilayer coatings have better corrosion resistance. This effect can be attributed to interfaces inside multilayer coatings that could potentially block the micropores and interrupt the corrosive medium path to the substrate $[24,77,78]$. Another possible reason is the partial oxidation of $\mathrm{Cr}$ into such as $\mathrm{Cr}_{2} \mathrm{O}_{3}$, which can passivate the surface and prevent further corrosion attack $[30,79]$. Due to the TiAlSiN coating prepared by the HiPIMS method exhibits a dense morphology and few growth defects (voids) (Fig. 2), and during the chemical attack, Cr easily forms dense $\mathrm{Cr}_{2} \mathrm{O}_{3}$ layer on the coating surface [79]. Therefore, the formation of the $\mathrm{Cr}_{2} \mathrm{O}_{3}$ protective layer may be the dominant reason for the improvement of the corrosion performance of the multilayer coatings. When the thicknesses of the Cr layers increased from $10 \mathrm{~nm}$ to $21 \mathrm{~nm}$, the corrosion current density of TiAlSiN/Cr multilayer coatings was further reduced. This change can be potentially explained by the findings that the thicker $\mathrm{Cr}$ layers have a higher probability of covering surface features more efficiently, thereby reducing the porosity of the coatings [80]. However, the corrosion current density increased, as the thicknesses of the $\mathrm{Cr}$ layers increased from $21 \mathrm{~nm}$ to $41 \mathrm{~nm}$. This may be because some voids are present and enlarged, as the thickness of $\mathrm{Cr}$ layers increases [81-83]. These results demonstrate that the TiAlSiN/Cr multilayer coatings have better corrosion resistance than the TiAlSiN coating and the coating with the Cr layers thickness of $21 \mathrm{~nm}$ exhibits superior corrosion resistance.

\section{Conclusions}

The TiAlSiN/Cr multilayer coatings with different thicknesses of $\mathrm{Cr}$ layers were prepared by HiPIMS and DCMS. The TiAlSiN layers were characterized as a mixture of nanocrystallites TiN and amorphous phase. Although the hardness of the TiAlSiN/Cr multilayer coatings decreases from the maximum of $34.5 \mathrm{GPa}$ for the single-layer TiAlSiN coating as the thickness of $\mathrm{Cr}$ layers increased, the TiAlSiN/Cr multilayer coatings showed a significantly improved toughness. As a result, while the TiAlSiN coating exhibited the best SPE resistance at the impact angle of $30^{\circ}$, the TiAlSiN/Cr multilayer coatings showed a significant improvement in the SPE resistance at impact angle of $90^{\circ}$ as well as corrosion resistance. We further identified that the TiAlSiN/Cr multilayer coatings with the $\mathrm{Cr}$ layer thickness of $21 \mathrm{~nm}$ showed the optimal comprehensive properties with high hardness, excellent toughness, erosion, and corrosion properties. Our study provides a potential method in design and optimizing SPE and corrosion resistance by controlling the thickness of the ductile metallic layer in the protective coatings with multilayer structure.

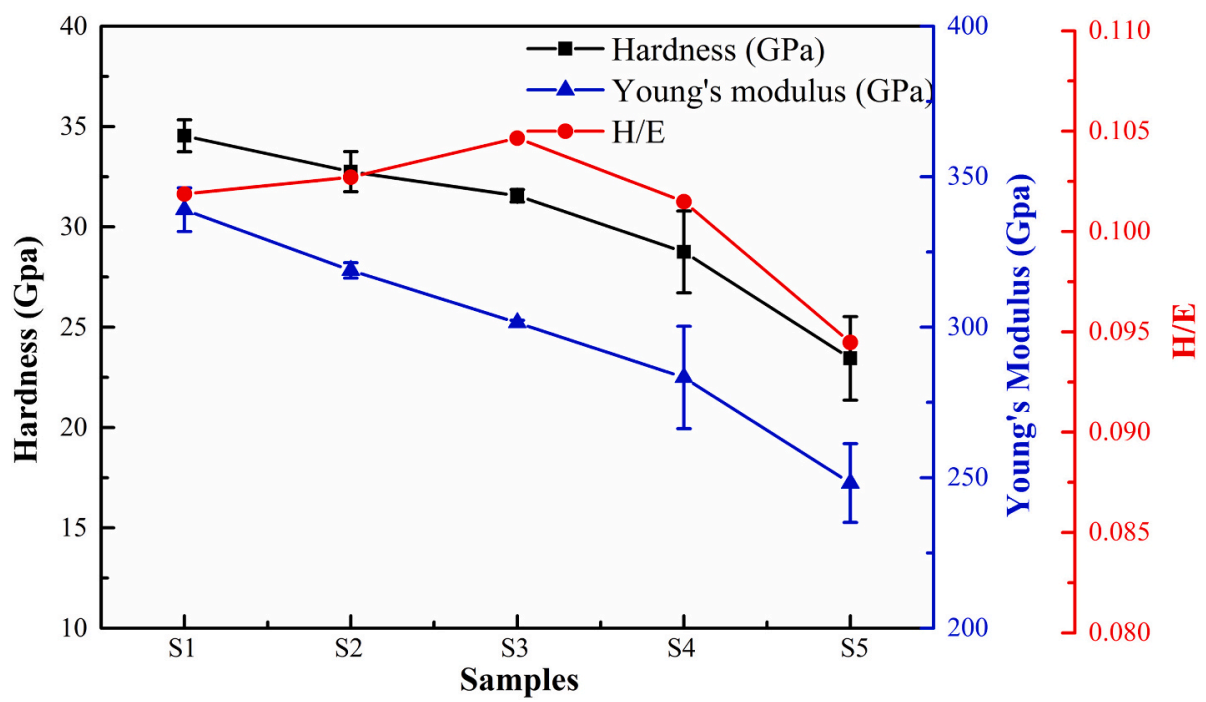

Fig. 4. Hardness, Young's modulus, and H/E ratio of TiAlSiN coating (S1) and TiAlSiN/Cr multilayer coatings with different thicknesses of Cr layers of $10 \mathrm{~nm}$ (S2), $21 \mathrm{~nm}(\mathrm{~S} 3), 30 \mathrm{~nm}(\mathrm{~S} 4)$, and $41 \mathrm{~nm}(\mathrm{~S} 5)$. 


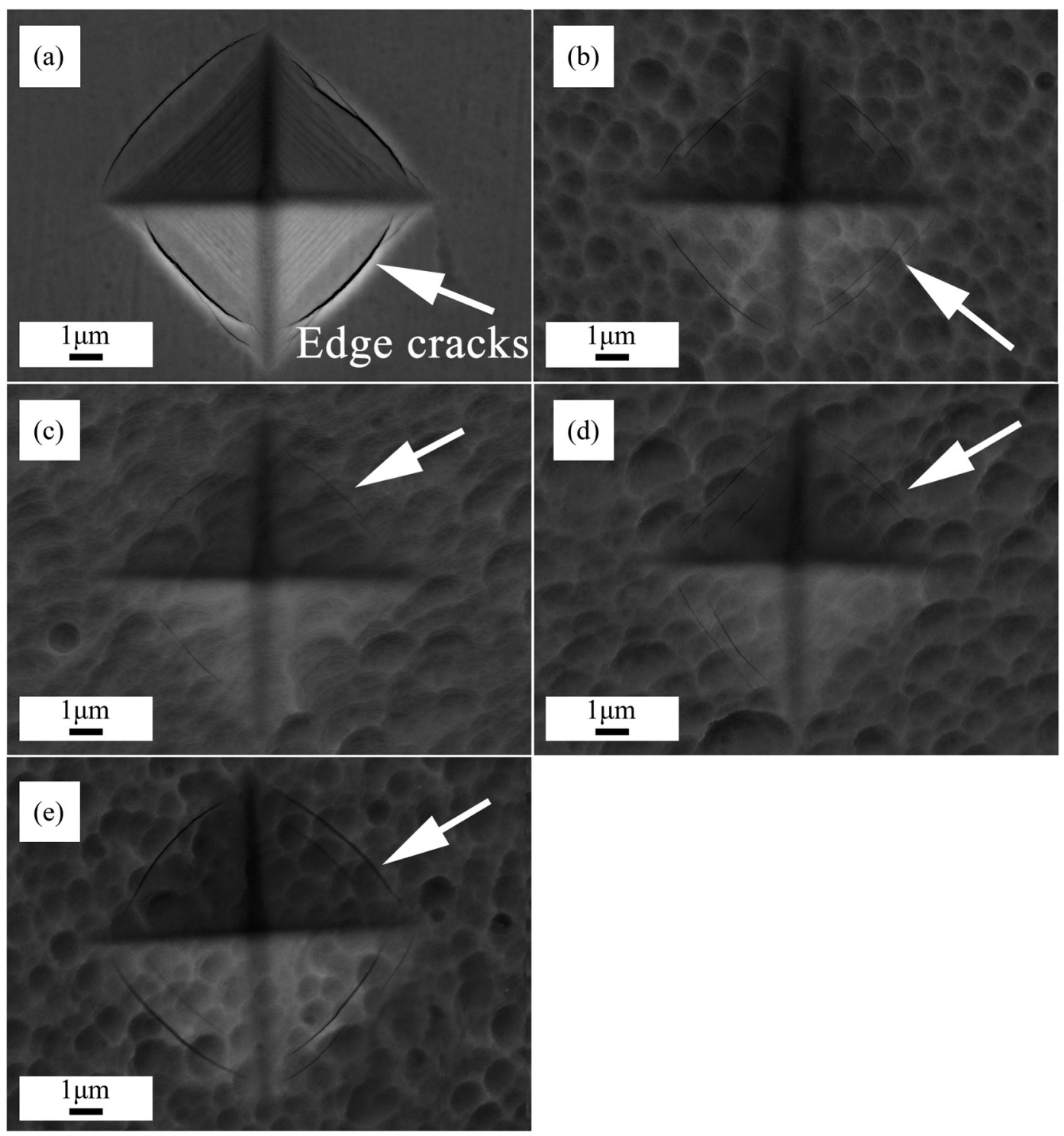

Fig. 5. The surface morphology of the indentation generated by Vickers indenter of TiAlSiN coating (a) and TiAlSiN/Cr multilayer coatings with different thicknesses of Cr layers of $10 \mathrm{~nm}(\mathrm{~b}), 21 \mathrm{~nm}(\mathrm{c}), 30 \mathrm{~nm}(\mathrm{~d})$, and $41 \mathrm{~nm}(\mathrm{e})$.

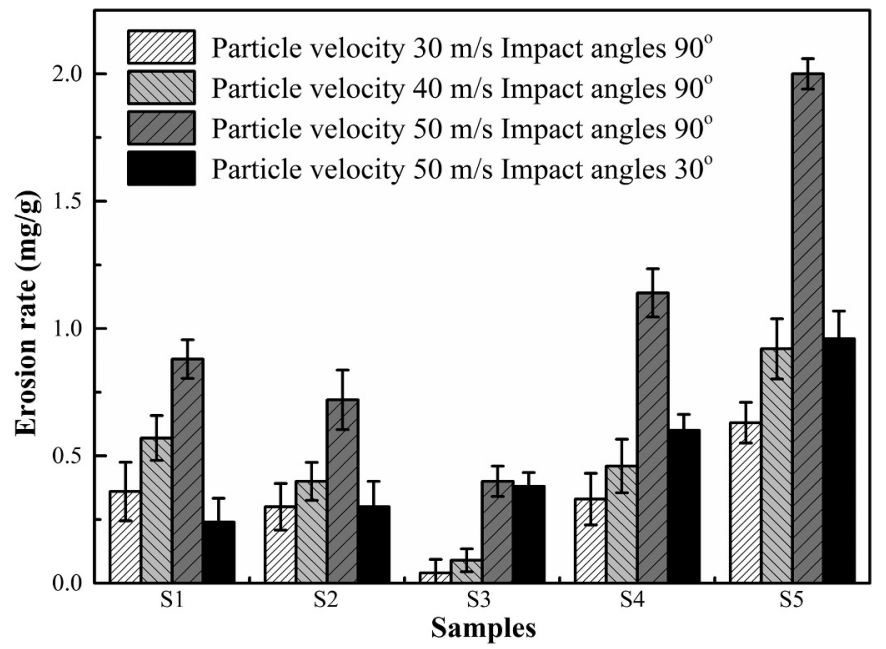

Fig. 6. Erosion rates of TiAlSiN coating (S1) and TiAlSiN/Cr multilayer coatings with different thicknesses of Cr layers of $10 \mathrm{~nm}$ (S2), $21 \mathrm{~nm}$ (S3), $30 \mathrm{~nm}$ (S4), and $41 \mathrm{~nm}(\mathrm{~S} 5)$.

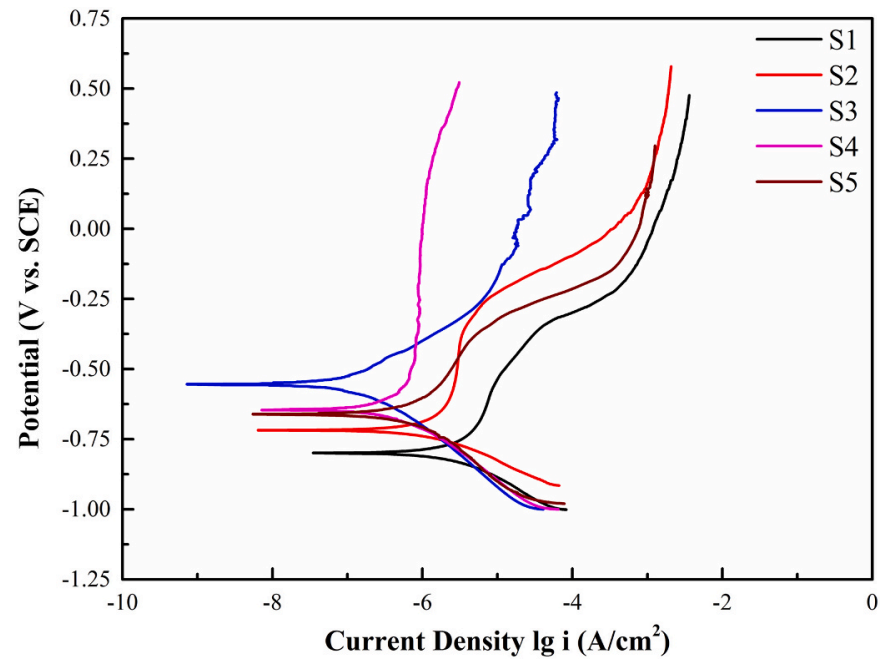

Fig. 7. Potentiodynamic polarization curves of TiAlSiN coating (S1) and TiAlSiN/Cr multilayer coatings with different thicknesses of Cr layers of $10 \mathrm{~nm}$ (S2), $21 \mathrm{~nm}$ (S3), $30 \mathrm{~nm}$ (S4), and $41 \mathrm{~nm}$ (S5) in $3.5 \% \mathrm{NaCl}$ solution. 
Table 2

Potentiodynamic polarization results of the TiAlSiN coating and TiAlSiN/Cr multilayer coatings.

\begin{tabular}{lll}
\hline Samples & $\mathrm{E}_{\text {corr }}(\mathrm{V})$ & $\mathrm{I}_{\text {corr }}\left(\mathrm{A} / \mathrm{cm}^{2}\right)$ \\
\hline S1 & -0.799 & $1.91 \times 10^{-6}$ \\
S2 & -0.718 & $9.62 \times 10^{-7}$ \\
S3 & -0.554 & $1.64 \times 10^{-7}$ \\
S4 & -0.646 & $3.89 \times 10^{-7}$ \\
S5 & -0.661 & $5.37 \times 10^{-7}$ \\
\hline
\end{tabular}

\section{CRediT authorship contribution statement}

Jiabin Gu:Conceptualization, Investigation, Methodology, Data curation, Writing - original draft.Liuhe Li:Funding acquisition, Methodology, Project administration.Meng Ai:Investigation, Methodology, Data curation.Yi Xu:Writing - review \& editing.Ye Xu:Writing - review \& editing, Methodology.Guodong Li:Methodology, Investigation.Dachen Deng:Investigation.Hui Peng:Investigation.Sida Luo:Investigation.Peipei Zhang:Investigation.

\section{Declaration of competing interest}

The authors declare that they have no known competing financial interests or personal relationships that could have appeared to influence the work reported in this paper.

\section{Acknowledgements}

This work was jointly supported by the National Science and Technology Major Project of China (2017-VII-0012-0108 and 2017-VII0003-0096).

\section{References}

[1] K.S. Tan, J.A. Wharton, R.J.K. Wood, Solid particle erosion-corrosion behaviour of a novel HVOF nickel aluminium bronze coating for marine applications-correlation between mass loss and electrochemical measurements, Wear 258 (2005) 629-640.

[2] A.S. Khanna, Introduction to High Temperature Oxidation and Corrosion, ASM International, 2002

[3] V. Bonu, M. Jeevitha, V.P. Kumar, G. Srinivas, Siju, H.C. Barshilia, Solid particle erosion and corrosion resistance performance of nanolayered multilayered Ti/TiN and TiAl/TiAlN coatings deposited on Ti6Al4V substrates, Surf. Coat. Technol. 387 (2020) 125531.

[4] R. Rajendran, Gas turbine coatings-an overview, Eng. Fail. Anal. 26 (2012) 355-369.

[5] L. Swadźba, A. Maciejny, B. Formanek, P. Liberski, P. Podolski, B. Mendala, H. Gabriel, A. Poznańska, Influence of coatings obtained by PVD on the properties of aircraft compressor blades, Surf. Coat. Technol. 78 (1996) 137-143.

[6] J.T. DeMasi-Marcin, D.K. Gupta, Protective coatings in the gas turbine engine, Surf. Coat. Technol. 68 (1994) 1-9.

[7] D. Wang, S. Lin, L. Liu, H. Yang, J. Shi, B. Jiang, K. Zhou, X. Zhang, Micro-nano multilayer structure design and solid particle erosion resistance performance of CrAlN $_{x} /$ CrAlN coating, Vacuum 172 (2020) 109064.

[8] D. Zhou, H. Peng, L. Zhu, H. Guo, S. Gong, Microstructure, hardness and corrosion behaviour of Ti/TiN multilayer coatings produced by plasma activated EB-PVD, Surf. Coat. Technol. 258 (2014) 102-107.

[9] E. Poursaeidi, A.M. Niaei, M. Lashgari, K. Torkashvand, Experimental studies of erosion and corrosion interaction in an axial compressor first stage rotating blade material, Appl. Phys. A Mater. Sci. Process. 124 (2018) 629.

[10] M.W. Reedy, T.J. Eden, J.K. Potter, D.E. Wolfe, Erosion performance and characterization of nanolayer ( $\mathrm{Ti}, \mathrm{Cr}$ ) $\mathrm{N}$ hard coatings for gas turbine engine compressor blade applications, Surf. Coat. Technol. 206 (2011) 464-472.

[11] E. Bousser, L. Martinu, J.E. Klemberg-Sapieha, Solid particle erosion mechanisms of protective coatings for aerospace applications, Surf. Coat. Technol. 257 (2014) $165-181$.

[12] V.R. Parameswaran, J.P. Immarigeon, D. Nagy, Titanium nitride coating for aero engine compressor gas path components, Surf. Coat. Technol. 52 (1992) 251-260.

[13] L. Swadźba, B. Formanek, H. Gabriel, P. Liberski, P. Podolski, Erosion- and corrosion-resistant coatings for aircraft compressor blades, Surf. Coat. Technol. 62 (1993) 486-492.

[14] S.S. Lin, K.S. Zhou, M.J. Dai, Structural, mechanical, and sand erosion properties of TiN/Zr/ZrN multilayer coatings, Vacuum 122 (2015) 179-186.

[15] Q. Yang, R. McKellar, Nanolayered CrAlTiN and multilayered CrAlTiN-AlTiN coatings for solid particle erosion protection, Tribol. Int. 83 (2015) 12-20.
[16] B. Borawski, J.A. Todd, J. Singh, D.E. Wolfe, The influence of ductile interlayer material on the particle erosion resistance of multilayered TiN based coatings, Wear 271 (2011) 2890-2898.

[17] X. Cao, W. He, B. Liao, H. Zhou, H. Zhang, C. Tan, Z. Yang, Sand particle erosion resistance of the multilayer gradient TiN/Ti coatings on Ti6Al4V alloy, Surf. Coat. Technol. 365 (2019) 214-221.

[18] M. Naveed, A. Obrosov, S. Weiß, Investigation of the wear resistance properties of $\mathrm{Cr} / \mathrm{CrN}$ multilayer coatings against sand erosion, Conf. Pap. Sci. 2015 (2015) 1-9.

[19] A. Feuerstein, A. Kleyman, Ti-N multilayer systems for compressor airfoil sand erosion protection, Surf. Coat. Technol. 204 (2009) 1092-1096.

[20] A. Leyland, A. Matthews, Thick Ti/TiN multilayered coatings for abrasive and erosive wear resistance, Surf. Coat. Technol. 70 (1994) 19-25.

[21] P. Wieciński, J. Smolik, H. Garbacz, K.J. Kurzydłowski, Erosion resistance of the nanostructured Cr/CrN multilayer coatings on Ti6Al4V alloy, Vacuum 107 (2014) $277-283$.

[22] Y. Gachon, P. Ienny, A. Forner, G. Farges, M.C.S. Catherine, A.B. Vannes, Erosion by solid particles of W/W-N multilayer coatings obtained by PVD process, Surf. Coat. Technol. 113 (1999) 140-148.

[23] Y.L. Chipatecua, J.J. Olaya, D.F. Arias, Corrosion behaviour of $\mathrm{CrN} / \mathrm{Cr}$ multilayers on stainless steel deposited by unbalanced magnetron sputtering, Vacuum 86 (2012) 1393-1401.

[24] M. Fenker, M. Balzer, H. Kappl, Corrosion protection with hard coatings on steel: past approaches and current research efforts, Surf. Coat. Technol. 257 (2014) $182-205$.

[25] I. Park, S.R. Choi, J.H. Suh, C. Park, K.H. Kim, Deposition and mechanical evaluation of superhard Ti-Al-Si-N nanocomposite films by a hybrid coating system, Thin Solid Films 447 (2004) 443-448.

[26] K. Su, D. Liu, H. Pang, T. Shao, Improvement on thermal stability of TiAlSiN coatings deposited by IBAD, Surf. Eng. 34 (2018) 504-510.

[27] Y.H. Yoo, D.P. Le, J.G. Kim, S.K. Kim, P. Van Vinh, Corrosion behavior of TiN, TiAlN, TiAlsiN thin films deposited on tool steel in the $3.5 \mathrm{wt} . \% \mathrm{NaCl}$ solution, Thin Solid Films 516 (2008) 3544-3548.

[28] K. Bobzin, T. Brögelmann, C. Kalscheuer, T. Liang, Post-annealing of (Ti, Al, Si) N coatings deposited by high speed physical vapor deposition (HS-PVD), Surf. Coat. Technol. 375 (2019) 752-762.

[29] K. Bobzin, T. Brögelmann, C. Kalscheuer, B. Yildirim, T. Liang, Deposition of a nanocomposite ( $\mathrm{Ti}, \mathrm{Al}, \mathrm{Si}) \mathrm{N}$ coating with high thickness by high-speed physical vapor deposition, Mater. Werkst. 51 (2020) 297-312.

[30] C. Liu, Q. Bi, H. Ziegele, A. Leyland, A. Matthews, Structure and corrosion properties of PVD Cr-N coatings, J. Vac. Sci. Technol. A 20 (2002) 772-780.

[31] V. Kouznetsov, K. Macak, J.M. Schneider, U. Helmersson, I. Petrov, A novel pulsed magnetron sputter technique utilizing very high target power densities, Surf. Coat. Technol. 122 (1999) 290-293.

[32] A.P. Ehiasarian, W.D. Münz, L. Hultman, U. Helmersson, I. Petrov, High power pulsed magnetron sputtered $\mathrm{CrN}_{\mathrm{x}}$ films, Surf. Coat. Technol. 163 (2003) 267-272.

[33] W.D. Münz, HIPIMS: the new PVD technology, Vak. Forsch. Prax. 20 (S1) (2008) 27.

[34] Y.P. Purandare, A.P. Ehiasarian, M.M. Stack, P.E. Hovsepian, CrN/NbN coatings deposited by HIPIMS: a preliminary study of erosion-corrosion performance, Surf. Coat. Technol. 204 (2010) 1158-1162.

[35] D. Eichner, A. Schlieter, C. Leyens, L. Shang, S. Shayestehaminzadeh, J.M. Schneider, Solid particle erosion behavior of nanolaminated $\mathrm{Cr}_{2} \mathrm{AlC}$ films, Wear 402 (2018) 187-195.

[36] C. Reinhard, A.P. Ehiasarian, P.E. Hovsepian, CrN/NbN superlattice structured coatings with enhanced corrosion resistance achieved by high power impulse magnetron sputtering interface pre-treatment, Thin Solid Films 515 (2007) 3685-3692.

[37] I.-L. Velicu, V. Tiron, B.G. Rusu, G. Popa, Copper thin films deposited under different power delivery modes and magnetron configurations: a comparative study, Surf. Coat. Technol. 327 (2017) 192-199.

[38] A. Matthews, R. Jones, S. Dowey, Modelling the deformation behaviour of multilayer coatings, Tribol. Lett. 11 (2) (2001) 103-106.

[39] J. Gu, L. Li, H. Miao, Y. Xu, Y. Xu, J. Sun, X. Wang, Z. He, Effect of $\mathrm{C}_{2} \mathrm{H}_{2} / \mathrm{N}_{2}$ partial pressure ratio on microstructure and mechanical properties of Ti-Al-Si-C-N coatings, Surf. Coat. Technol. 365 (2019) 200-207.

[40] Q. Ma, L. Li, Y. Xu, J. Gu, L. Wang, Y. Xu, Effect of bias voltage on TiAlSiN nanocomposite coatings deposited by HiPIMS, Appl. Surf. Sci. 392 (2017) 826-833.

[41] ASTM-G76, ASTM International, West Conshohocken, PA (2007) 6.

[42] A.W. Ruff, L.K. Ives, Measurement of solid particle velocity in erosive wear, wear 35 (1975) 195-199.

[43] S.Q. Wang, L. Chen, B. Yang, K.K. Chang, Y. Du, J. Li, T. Gang, Effect of Si addition on microstructure and mechanical properties of Ti-Al-N coating, Int. J. Refract. Met. Hard Mater. 28 (2010) 593-596.

[44] G. Li, L. Li, M. Han, S. Luo, J. Jin, L. Wang, J. Gu, H. Miao, The performance of TiAlSiN coated cemented carbide tools enhanced by inserting Ti interlayers, Metals 9 (2019) 918.

[45] T. Mori, S. Fukuda, Y. Takemura, Improvement of mechanical properties of Ti/TiN multilayer film deposited by sputtering, Surf. Coat. Technol. 140 (2001) 122-127.

[46] J. Pelleg, L.Z. Zevin, S. Lungo, Reactive-sputter-deposited TiN films on glass substrates, Thin Solid Films 197 (1991) 117-128.

[47] X. Pang, L. Zhang, H. Yang, K. Gao, A.A. Volinsky, Residual stress and surface energy of sputtered TiN films, J. Mater. Eng. Perform. 24 (2015) 1185-1191.

[48] U. Selvadurai, W. Tillmann, G. Fischer, T. Sprute, The influence of multilayer design on residual stress gradients in Ti/TiAlN systems, Mater. Sci. Forum 768-769 (2013) 264-271.

[49] G. Abadias, Y.Y. Tse, Ph. Guerin, V. Pelosin, Interdependence between stress, 
preferred orientation, and surface morphology of nanocrystalline TiN thin films deposited by dual ion beam sputtering, J. Appl. Phys. 99 (2006) 113519.

[50] P. Patsalas, C. Gravalidis, S. Logothetidis, Surface kinetics and subplantation phenomena affecting the texture, morphology, stress, and growth evolution of titanium nitride films, J. Appl. Phys. 96 (2004) 6234.

[51] S. Vepřek, S. Reiprich, L. Shizhi, Superhard nanocrystalline composite materials: the TiN/ $/ \mathrm{Si}_{3} \mathrm{~N}_{4}$ system, Appl. Phys. Lett. 66 (1995) 2640-2642.

[52] S. Vepřek, New development in superhard coatings: the superhard nanocrystallineamorphous composites, Thin Solid Films 317 (1998) 449-454.

[53] S. Carvalho, L. Rebouta, A. Cavaleiro, L.A. Rocha, J. Gomes, E. Alves, Microstructure and mechanical properties of nanocomposite ( $\mathrm{Ti}, \mathrm{Si}, \mathrm{Al}) \mathrm{N}$ coatings, Thin Solid Films 398 (2001) 391-396.

[54] F. Vaz, L. Rebouta, P. Goudeau, J. Pacaud, H. Garem, J.P. Rivière, A. Cavaleiro, E. Alves, Characterisation of $\mathrm{Ti}_{1-x} \mathrm{Si}_{\mathrm{x}} \mathrm{N}_{\mathrm{y}}$ nanocomposite films, Surf. Coat. Technol. 133 (2000) 307-313.

[55] Z.J. Liu, P.W. Shum, Y.G. Shen, Hardening mechanisms of nanocrystalline Ti-Al-N solid solution films, Thin Solid Films 468 (2004) 161-166.

[56] A. Leyland, A. Matthews, On the significance of the H/E ratio in wear control: a nanocomposite coating approach to optimised tribological behavior, Wear 246 (2000) 1-11.

[57] A. Leyland, A. Matthews, Design criteria for wear-resistant nanostructured and glassy-metal coatings, Surf. Coat. Technol. 177 (2004) 317-324.

[58] Q. Meng, P. Malinovskis, N. Nedfors, F. Mao, M. Andersson, Y. Sun, U. Jansson, Characterization of amorphous Zr-Si-C thin films deposited by DC magnetron sputtering, Surf. Coat. Technol. 261 (2015) 227-234.

[59] Y. Kong, X. Tian, C. Gong, P.K. Chu, Enhancement of toughness and wear resistance by $\mathrm{CrN} / \mathrm{CrCN}$ multilayered coatings for wood processing, Surf. Coat. Technol. 344 (2018) 204-213

[60] T. Guo, C. Kong, X. Li, P. Guo, Z. Wang, A. Wang, Microstructure and mechanical properties of Ti/Al co-doped DLC films: dependence on sputtering current, source gas, and substrate bias, Appl. Surf. Sci. 410 (2017) 51-59.

[61] C. Dang, Y. Yao, T. Olugbade, J. Li, L. Wang, Effect of multi-interfacial structure on fracture resistance of composite TiSiN/Ag/TiSiN multilayer coating, Thin Solid Films 653 (2018) 107-112.

[62] S. Bhowmick, A.N. Kale, V. Jayaram, S.K. Biswas, Contact damage in TiN coatings on steel, Thin Solid Films 436 (2003) 250-258.

[63] H. Holleck, V. Schier, Multilayer PVD coatings for wear protection, Surf. Coat. Technol. 76 (1995) 328-336.

[64] Y.X. Wang, S. Zhang, Toward hard yet tough ceramic coatings, Surf. Coat. Technol. 258 (2014) 1-16.

[65] C. Dang, J. Li, Y. Wang, J. Chen, Structure, mechanical and tribological properties of self-toughening TiSiN/Ag multilayer coatings on Ti6Al4V prepared by arc ion plating, Appl. Surf. Sci. 386 (2016) 224-233.

[66] I.M. Hutchings, Ductile-brittle transitions and wear maps for the erosion and abrasion of brittle materials, J. Phys. D. Appl. Phys. 25 (1992) A212.

[67] A.A. El-Rahman, R. Wei, Effect of ion bombardment on structural, mechanical, erosion and corrosion properties of Ti-Si-C-N nanocomposite coatings, Surf. Coat.
Technol. 258 (2014) 320-328.

[68] S. Hassani, J.E. Klemberg-Sapieha, M. Bielawski, W. Beres, L. Martinu, M. Balazinski, Design of hard coating architecture for the optimization of erosion resistance, Wear 265 (2008) 879-887.

[69] A.P. Anaraki, J. Kadkhodapour, N.K. Farahani, Study of solid particle impact effects and coating thickness on the erosion damage, Proc. Inst. Mech. Eng. C J. Mech. Eng. Sci. 228 (2014) 2861-2870.

[70] Y.I. Oka, K. Okamura, T. Yoshida, Practical estimation of erosion damage caused by solid particle impact: part 1: effects of impact parameters on a predictive equation, Wear 259 (2005) 95-101.

[71] E. Bousser, L. Martinu, J.E. Klemberg-Sapieha, Effect of erodent properties on the solid particle erosion mechanisms of brittle materials, J. Mater. Sci. 48 (2013) 5543-5558.

[72] J.S. Grewal, B.S. Sidhu, S. Prakash, High temperature erosion performance of nanostructured and conventional TiAlN coatings on AISI-304 boiler steel substrate, Trans. Indian Inst. Metals 67 (2014) 889-902.

[73] Q. Yang, D.Y. Seo, L.R. Zhao, X.T. Zeng, Erosion resistance performance of magnetron sputtering deposited TiAlN coatings, Surf. Coat. Technol. 188 (2004) $168-173$.

[74] J. Du, X. Zhu, P. Zhang, Z. Cai, Microstructure and erosion resistance performance of ZrAlN/Cu coating, Phys. Procedia 32 (2012) 757-765.

[75] I. Finnie, J. Wolak, Y. Kabil, Erosion of metals by solid particles, J. Mater. 2 (1967) $682-700$

[76] C. Liu, A. Leyland, Q. Bi, A. Matthews, Corrosion resistance of multi-layered plasma-assisted physical vapour deposition TiN and CrN coatings, Surf. Coat. Technol. 141 (2001) 164-173.

[77] T. Xie, S. Mao, C. Yu, S. Wang, Z. Song, Structure, corrosion, and hardness properties of Ti/Al multilayers coated on NdFeB by magnetron sputtering, Vacuum 86 (2012) 1583-1588.

[78] J. Creus, E.H. Top, C. Savall, P. Refait, C. Ducros, F. Sanchette, Mechanical and corrosion properties of dc magnetron sputtered $\mathrm{Al} / \mathrm{Cr}$ multilayers, Surf. Coat. Technol. 202 (2008) 4047-4055.

[79] G.H. Song, X.P. Yang, G.L. Xiong, Z. Lou, L.J. Chen, The corrosive behavior of Cr/ CrN multilayer coatings with different modulation periods, Vacuum 89 (2013) $136-141$.

[80] S.E. Potts, L. Schmalz, M. Fenker, B. Díaz, J. Światowska, V. Maurice, A. Seyeux, P. Marcus, G. Radnóczi, L. Tóth, W.M.M. Kessels, Ultra-thin aluminium oxide films deposited by plasma-enhanced atomic layer deposition for corrosion protection, $\mathrm{J}$. Electrochem. Soc. 158 (2011) C132-C138.

[81] R. Messier, A.P. Giri, R.A. Roy, Revised structure zone model for thin film physica structure, J. Vac. Sci. Technol. A 2 (1984) 500-503.

[82] C.C. Ting, S.Y. Chen, D.M. Liu, Structural evolution and optical properties of $\mathrm{TiO}_{2}$ thin films prepared by thermal oxidation of sputtered Ti films, J. Appl. Phys. 88 (8) (2000) 4628-4633.

[83] H. Savaloni, H. Kangarloo, Influence of film thickness, substrate temperature and nano-structural changes on the optical properties of UHV deposited Ti thin films, J. Phys. D. Appl. Phys. 40 (1) (2007) 203-214. 